\title{
On the Validation of SPDM Task Verification Facility
}

\author{
Ou Ma* \\ New Mexico State University \\ Las Cruces, NM 88003-3450 \\ e-mail: oma@nmsu.edu \\ Jiegao Wang, Sarthak Misra, \\ and Michael Liu \\ MD Robotics Ltd. \\ 9445 Airport Road \\ Brampton, Canada L6S 4J3 \\ e-mail: mliu@mdrobotics.ca \\ Received 29 April 2003; accepted 5 January 2004
}

\begin{abstract}
This paper describes a methodology for validating a ground-based, hardware-in-theloop, space-robot simulation facility. This facility, called "SPDM task verification facility," is being developed by the Canadian Space Agency for the purpose of verifying the contact dynamics performance of the special purpose dexterous manipulator (SPDM) performing various maintenance tasks on the International Space Station because the real SPDM cannot be physically tested for 3D operations on the ground due to the gravity. The facility uses a high-fidelity SPDM mathematical model, known as the "truth model" of the space robot, to drive a hydraulic robot to mimic the space robot performing contact operations. In this research different techniques were studied for practically verifying that the complex simulation facility preserves the dynamics of the truth model of the space robot for space-representative contact robotic tasks. Based upon the study and many years of experience in developing and verifying space robotic systems, a practical validation strategy including detailed test cases was developed along with a set of quantitative criteria for judging the validation test results. @ 2004 Wiley Periodicals, Inc.
\end{abstract}

\section{INTRODUCTION}

Special purpose dexterous manipulator (SPDM), shown in Figure 1, is a 15-degree-of-freedom, dual-

*To whom all correspondence should be addressed. arm, advanced space robot. ${ }^{1}$ It is designed to perform external maintenance tasks on the International Space Station. The robot is developed by MD Robotics Ltd. (MDR) of Canada for the Canadian Space Agency (CSA) as part of Canada's contribution to the 


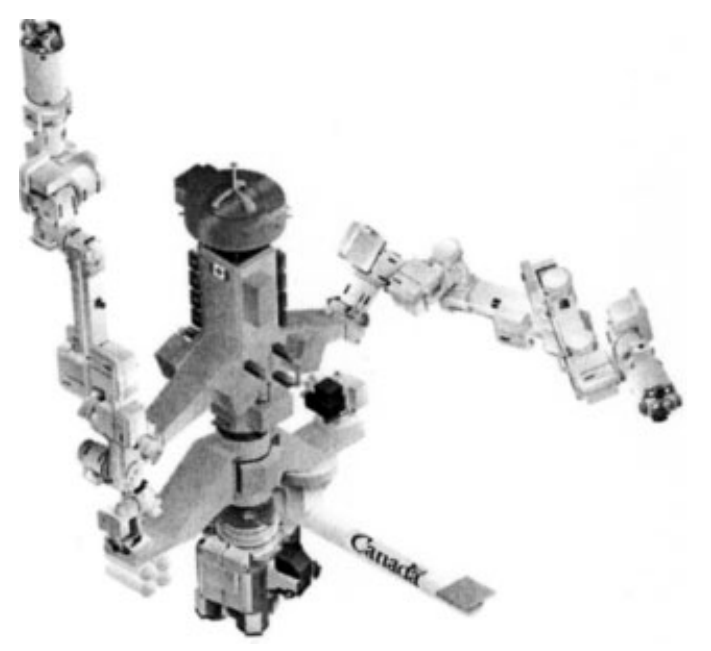

Figure 1. Special purpose dextrous manipulator (SPDM).

International Space Station Program. ${ }^{2}$ The flight unit of the robot has been completed and is currently scheduled to be launched in 2006 .

Like the other major space manipulators, the SPDM cannot be tested for general 3D tasks on the ground because it is not designed to operate under normal gravity condition. Instead, intensive com- puter simulations have to be employed to enhance the design and to finally verify the performance requirements. The accuracy of a purely software-based computer simulation depends on the accuracy of the mathematical models used in the simulation. It is very difficult to precisely model all the details of a complex space robot hardware like SPDM and its working environment, which has lots of nonlinearities and uncertainties. A special difficult area for verification is the contact-impact dynamics. To overcome this difficult technical problem, the Canadian Space Agency is developing a special hardware-in-the-loop simulation facility-SPDM Task Verification Facility (STVF), shown in Figure 2. It is based on a concept of hybrid simulation simultaneously using both mathematical model and real hardware. The primary purpose of the STVF is to verify the dynamics (especially contact dynamics) of the robotic tasks to be carried out by the SPDM on the Space Station. It will also be used for the development and verification of the robot's operation procedures, crew and ground personnel training, and mission analysis. ${ }^{3,4}$ The facility is currently in the final integration and test phase and will be delivered in late 2003. The STVF is an integrated space-representative robotic simulation facility combining both software- and hardware-

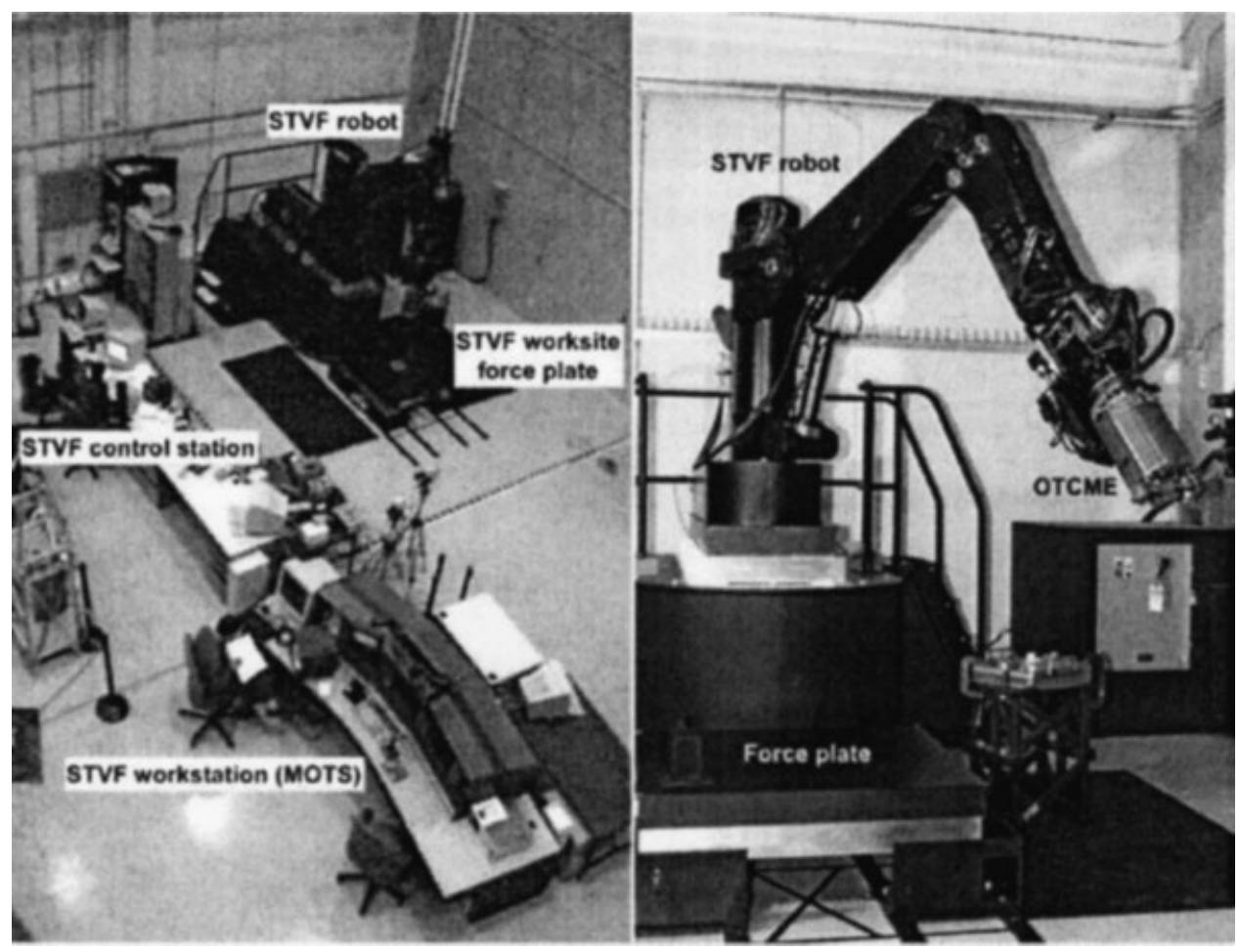

Figure 2. SPDM task verification facility (STVF). An overview of the facility (left) and the hydraulic ground robot (right). 


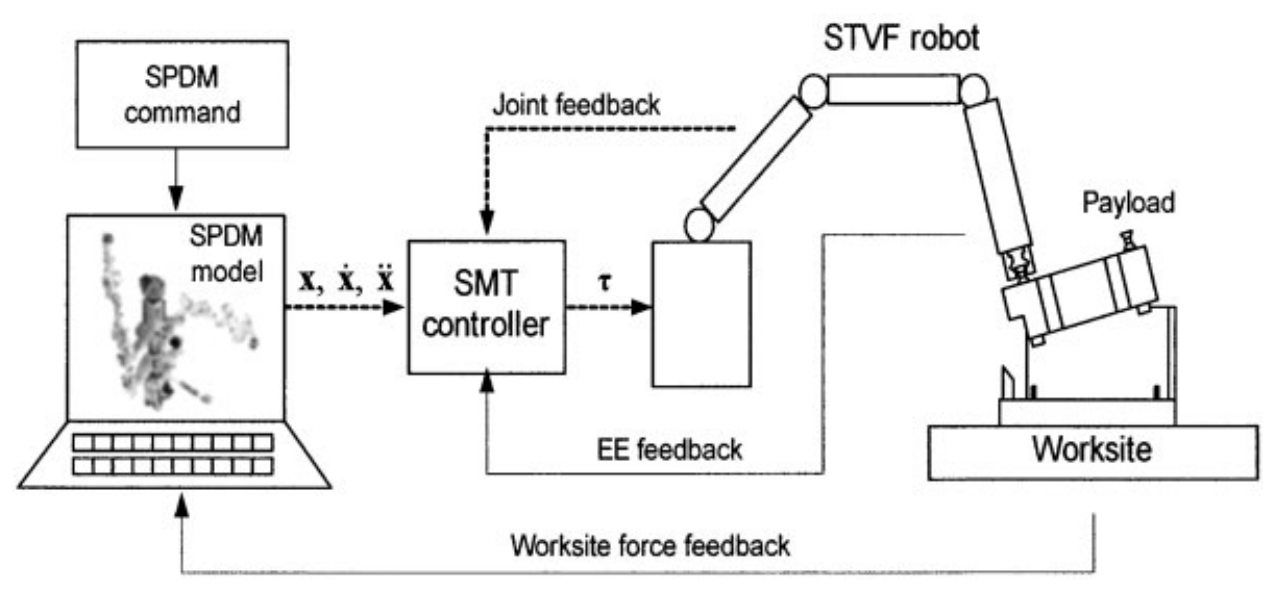

Figure 3. Concept of the STVF.

simulations. The software-simulation is performed based on the math model of the SPDM hardware and its control software (flight code). The hardwaresimulation, as shown in Figure 3, uses a highstiffness, hydraulic-drive ground robot, which is driven by the software simulation, to mimic SPDM performing robotic tasks using a realistic payload and worksite hardware. The loop between the softwareand hardware-simulations is closed by feeding the physically measured contact forces into the software-simulator. ${ }^{3,4}$

The concept of hardware-in-the-loop simulation has been developed and applied in studies of dynamic performance of space systems in the recent years. NASA built a pilot-in-the-loop facility to investigate the berthing of Space Shuttle into the Space Station by the Shuttle Remote Manipulator System (Canadarm). ${ }^{5}$ The berthing operations were performed using the real hardware driven by a simulation model of the Canadarm. A prediction-based feed-forward filter was used to make a ground-based hydraulic parallel manipulator to generate contact forces and rebound velocities that match those expected during the same on-orbit operations. ${ }^{6}$ DLR (German Space Center) also built a hardware-in-theloop simulator to simulate robotic contact operations in space. ${ }^{7}$ Their study demonstrated the criticalness of a fast data sampling rate for the stability of such a software-hardware hybrid simulation. The greatest challenge of the STVF is to guarantee that the ground robot will dynamically behave like the simulated space robot during various delicate contact tasks. In order to achieve this goal, many advanced robotics technologies have been used in the facility such as torque-controlled joint servos, computed torque con- trol with Cartesian linearization, robust control, high bandwidth and precision force sensors, and high precision motion sensors, etc. The STVF development team has theoretically and experimentally shown in principle that such an integrated hardware-in-theloop simulation facility is capable of achieving its design goal. ${ }^{8}$ However, since the theoretical proof and the experimental demonstration reported in that paper were limited to 2-degree-of-freedom systems only, the final conclusion about its validity for the real SPDM system will have to rely on the validation exercise after the facility is fully integrated. The authors were responsible for studying and developing a methodology to validate this facility.

The objective of this research work is to develop test methodology and procedure to validate that the facility is capable of accurately simulating SPDM onorbit behavior during contact tasks. One of the main challenges we are facing is to quantitatively define and measure what we intend to check. Another main challenge is that we will have to develop the quantitative criteria (tolerances for acceptable errors) for judging a test as pass or fail. Based upon two decades of experience in validating space robot simulations and upon the specifics of the STVF and SPDM systems, we developed a series of validation test concepts and procedures. The complexity of these tests gradually increases from free-space motion to partially constrained motion to full ORU contact tasks. We also developed two levels of criteria for judging the validation test results. The development is an open process keeping the STVF developers and users as well as the SPDM developers and users in the loop, 


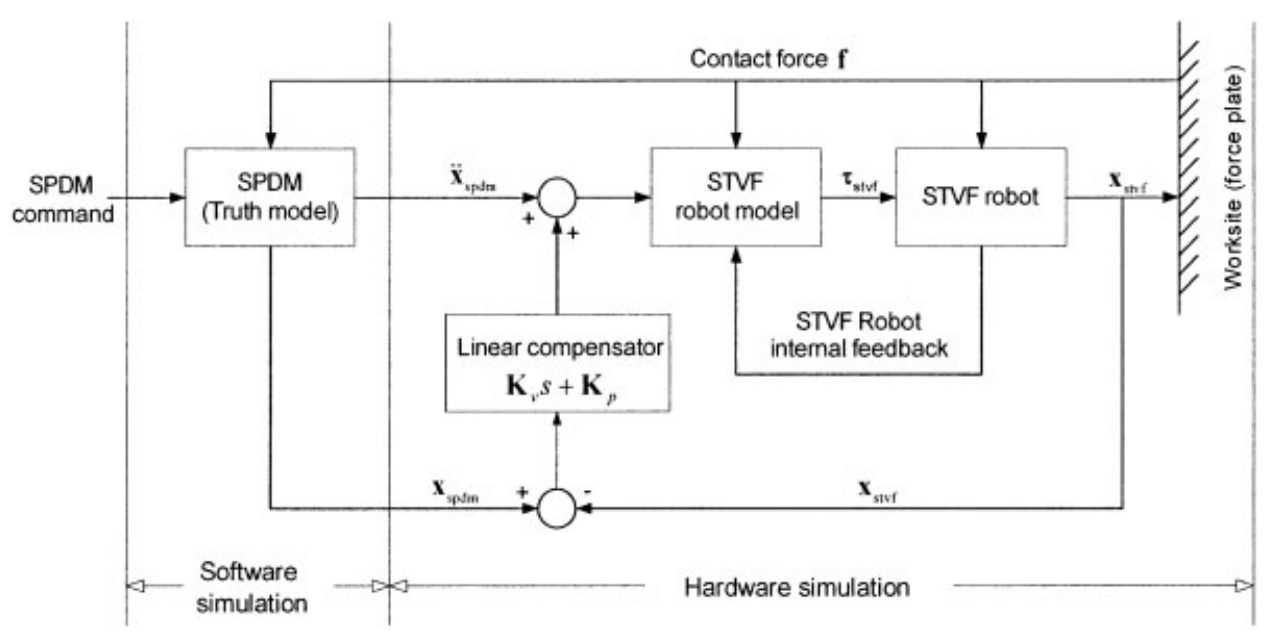

Figure 4. Overall control system of the STVF.

so that we can maximize ideas, expertise, and experience from different directions and, therefore, result in an optimal validation plan.

The paper first addresses the main challenges of the validation, starting from the next section. It then describes the validation methods including the main test concepts and their objectives. Finally, it discusses the criteria to be used to judge the pass or failure of individual test cases.

\section{VALIDATION OBJECTIVES AND MAJOR CONCERNS}

The primary goal of the validation process is to experimentally demonstrate that the STVF preserves the SPDM on-orbit dynamics. That is, the STVF hardware robot is capable of precisely reproducing dynamic characteristics of the SPDM as if it is in space performing both contact and noncontact robotic tasks.

The overall control system of the STVF is illustrated in Figure 4. In the figure, any variable with subscript "spdm" has the SPDM data coming from the simulation using the truth SPDM model. Variables with subscript "stvf" are from the STVF robot hardware. The key for the STVF control system is that its closed-loop transfer function is close to identity in the frequency range of interest. The controller consists of three major parts:

(1) The computed-torque feed-forward loop. In this feed-forward loop, the controller takes the computer-generated SPDM tip acceleration as its input and computes the required STVF robot's joint torques using the dynamics model of the STVF robot. The computed torques are then fed forward into the robot to actuate the robot following the input acceleration. Obviously, if the STVF robot model is perfect (i.e., perfectly matching the robot hardware), the STVF robot tip should track the simulated acceleration of the SPDM tip in the absence of contact force.

(2) The contact force feedback loop. In a contact task, the contact force from the worksite physically exerts on the STVF robot. The contact force will be sensed by the force plate, transformed to the POR frame of the STVF robot, and fed back into the STVF robot model in order to compensate the force acting on the STVF robot. The same force is also fed back into the SPDM simulation model as if the force is acting on the SPDM tip. If the force feedback gain is close to one and the force plate senses the contact force precisely, the physical contact force acting on the robot should be completely compensated. The hardware robot will keep tracking the simulated SPDM without being disturbed by the physical contact force on its tip. In order to sense the contact force precisely, the force plate was made to be highly accurate $(0.5 \mathrm{~N})$ and highly responsive $(1000 \mathrm{~Hz})$.

(3) The position and velocity feedback loop. This is a feedback loop used to keep the STVF robot tip motion on track of the simulated SPDM tip motion. As shown in the diagram, the tip acceleration of the STVF robot is

$$
\ddot{\mathbf{x}}_{\mathrm{stvf}}=\ddot{\mathbf{x}}_{\mathrm{spdm}}+\mathbf{K}_{v}\left(\dot{\mathbf{x}}_{\mathrm{spdm}}-\dot{\mathbf{x}}_{\mathrm{stvf}}\right)+\mathbf{K}_{p}\left(\mathbf{x}_{\mathrm{spdm}}-\mathbf{x}_{\mathrm{stvf}}\right)+\boldsymbol{\delta},
$$

where $\boldsymbol{\delta}$ is the error between the STVF robot model and the SFVF robot itself. If the robot model perfectly 
matches its hardware, $\boldsymbol{\delta}$ becomes zero and the transform function of the feedforward loop becomes identity. As a result, the tracking error $\mathbf{x}_{\text {spdm }}-\mathbf{x}_{\text {stvf }}$ can be easily under control by adjusting the feedback gains.

Based upon the above outlined principle of the STVF control system and our engineering experience, the major concerns of its validity in mimic SPDM dynamics would be in the following three aspects:

(a) It is very difficult to precisely model all the hardware components of the hydraulic STVF robot, which have many nonlinearities and uncertainties. As a result, the computed-torque (Cartesian linearization) feed-forward loop may not be able to fully compensate the nonlinear dynamics of the hardware robot.

(b) Without contact, the STVF system reduces to a master-slaver system and, thus, its capability of tracking the SPDM simulation responses can be easily verified through experiment. However, with the presence of contact, the contact-force feedback loop makes the system no longer a master-slaver system although it is still expected that the simulation model will remain the "master" in principle. It is a natural concern that the force feedback loop might change the dynamic characteristics of the SPDM unless both robots (the SPDM in simulation model and the STVF robot in hardware) have the same impedance at their tips. This has to be verified in the validation.

(c) The STVF robot is designed to track the motion of the simulated SPDM regardless of its tip forcemoment because the real contact force-moment is measured only from the worksite of the hardware robot as opposed to from its tip. In other words, the closed-loop system has to be able to reject any kind of force exerted on the tip of the STVF robot while it still smoothly tracks the simulated SPDM motion. For example, when the STVF simulates an unloaded, free-space motion of the SPDM, the dynamic responses of the STVF robot should remain the same, no matter what kind of payload hanging on its tip or what kind of force exerting on its tip during the simulation.

\section{APPROACHES AND CONSIDERATIONS}

Before designing validation test cases, we must first decide what validation approaches are to be used and what are the most important technical issues to be addressed in the validation.

\subsection{Validation Approaches}

Based upon different types of reference sources for comparing to, we have four possible approaches, namely, "hardware versus analysis," "hardware versus experiment," "hardware versus simulation," and "hardware versus flight" validations. Here the term "hardware" represents the STVF. Due to the high complexity of the STVF facility, it is impossible to analytically model the integrated system dynamics unless we impose significant simplification and massive assumptions, which will, without doubt, add alternative uncertainties about the validity of the analysis results. Therefore, "hardware versus analysis" approach does not apply here. "Hardware versus experiment" approach requires another hardware test system as the reference and, thus, it will likely be very costly, especially considering the fact that the reference system has to be validated as well. "Hardware versus simulation" approach requires another validated simulator as reference. The $\mathrm{MDSF}^{9}$ is a good reference because the facility has been validated using all the above-mentioned approaches and its SPDM model on MDSF has been accepted as the truth model for the International Space Station Program. "Hardware versus flight" approach is certainly the most favorable approach. However, the flight data will not be available until the SPDM is launched hopefully in 2006 and many SPDM verification tasks should be done by the STVF before the launch of the SPDM. Therefore, the "hardware versus flight" approach is not feasible for now. As a result, the "hardware versus simulation" approach is naturally the best one among all the four possible approaches. It should be emphasized that the approach of using simulation to verify the STVF hardware system is valid because the STVF is designed for tracking the SPDM simulation.

In order to be cost-effective, and also to fit into CSA's overall schedule of the Space Station Program, it is proposed to generate the validation plan in four phases:

Phase 1: In this phase, preliminary validation concepts are developed by MDR and a draft validation plan is written and issued. This plan will contain initial test specifications, but not the validation criteria. This phase is characterized as a proposal phase.

Phase 2: In this phase, individual test cases and the related methods and procedure are developed by MDR; the basic concepts proposed in the preliminary validation plan from Phase 1 will thoroughly be reviewed by CSA and MDR together. As a result of the review, changes to the concepts and specifications will be made based on all the individual test cases and the related methods and procedure. SPDM simulations for all the planned test cases will be set up and tried on the MDSF. Simulation results are studied in 
order to identify potential problems and understand the expected outcome. Besides, validation criteria will also be developed in this phase. This phase will be concluded with the delivery of the first version of the full validation plan. Among all the four phases, this phase is characterized as a major development phase. We have completed this phase.

Phase 3: In this phase, MDR will meet with CSA and go through a thorough review and discussion of the validation plan developed in Phase 2. As a result of the review, modifications to the validation criteria and some test cases may be recommended and incorporated into the plan. The actual validation work may start during this phase, and initial report on the validation results will be issued.

Phase 4: After the launch of the SPDM and the flight data being available, the MDSF-based SPDM model would be updated based on flight data. By that time, the SPDM truth model will no longer be an assumption but instead a reality. In turn, the validation plan will also have to be revised to reflect any new updates in the SPDM model. This phase will conclude with the final version of the plan together with the final report on the validation results.

\subsection{Technical Considerations}

Three important aspects have to be considered when the validation plan is designed. They are SPDM system configurations, SPDM control modes, and SPDM motion trajectories. These are the important considerations for evaluating the performance of the STVF system and the SPDM system. For all of the operation-related recommendations described in this section, satisfactory MDSF simulation study has been conducted. This is to ensure that all the foreseeable technical problems have been resolved before the STVF physical tests start. In fact, pretest simulation discovered many potential problems and helped us to optimize the detailed test plan.

\subsubsection{System Configurations}

The SPDM has two arms and it will be mostly operated while its body is attached to the working tip of the Space Station Remote Manipulator System (SSRMS), ${ }^{2}$ a $17 \mathrm{~m}$ long robotic arm, also called Canadarm2. There are, thus, three arms in the system, which can form many combinations of different multi-arm configurations. For the same ORU (i.e., Orbital Replaceable Unit, a general name for any modular space hardware unit) task, the performance or dynamic response of the SPDM may be quite different from one configuration to another. Although the validation test cases cannot cover all possible system configurations, they will have to reflect the most typical ones. The following are the recommended typical three-arm system configurations:

1. SPDM standing on the Space Station with one arm in operation and the other arm free,

2. SPDM standing on the Space Station with one arm in operation and the other arm anchored to the station for stabilization,

3. SPDM standing on the tip of the Canadarm2 with one arm in operation and the other arm free, and

4. SPDM standing on the tip of the Canadarm2 with one arm in operation and the other arm anchored to the station for stabilization.

Consideration is given to the worst system configurations when planning the validation test runs. From the control point of view, the worst systemconfiguration is when the SPDM operates while it is attached to the tip of the Canadarm 2 because in such a configuration the system has the lowest structural frequencies. For the STVF robot, the abovementioned system configuration of the space robots is not a concern because the ground robot does not need to have the same kinematic configuration as the space robots and its operational workspace is only a small portion of the entire reachable workspace of the ground robot. Therefore, the STVF robot can always be put in its best arm configuration for optimal performance.

\subsubsection{SPDM Control Modes}

The SPDM has a variety of different control modes and features, which will be used in ORU tasks. ${ }^{10}$ Those modes and features are listed below:

-Limp

-Standby

-Single joint rate mode (SJRM)

-Manual augmented mode (MAM)

-Operator commanded POR mode (OCPM)

-Prestored POR automatic mode (PPAM)

-Operator commanded joint mode (OCJM)

-Prestored joint automatic mode (PJAM)

-Force moment accommodation feature

(FMA)

-Line tracking feature

ture (POHS)

-Position and orientation hold selection fea- 
Table I. Summary of STVF validation test cases.

\begin{tabular}{|c|c|c|c|}
\hline $\begin{array}{l}\text { Run } \\
\text { ID }\end{array}$ & $\begin{array}{c}\text { Test } \\
\text { category }\end{array}$ & Main purpose & $\begin{array}{l}\text { No. of } \\
\text { runs }\end{array}$ \\
\hline$\overline{\text { FS }}$ & $\begin{array}{l}\text { Free-space } \\
\text { test }\end{array}$ & $\begin{array}{l}\text { Validate STVF capability of simulating } \\
\text { SPDM free-space motion }\end{array}$ & 7 \\
\hline $\mathrm{RC}$ & $\begin{array}{l}\text { Rigidly } \\
\text { constrained test }\end{array}$ & $\begin{array}{l}\text { Validate STVF capability of simulating } \\
\text { SPDM fully constrained motion }\end{array}$ & 2 \\
\hline $\mathrm{AF}$ & $\begin{array}{l}\text { Applied force } \\
\text { test }\end{array}$ & $\begin{array}{l}\text { Validate STVF capability of simulating } \\
\text { SPDM dynamic response to applied tip } \\
\text { forces (virtual contact motion) }\end{array}$ & 4 \\
\hline SCD & $\begin{array}{l}\text { Simple } \\
\text { contact test }\end{array}$ & $\begin{array}{l}\text { Validate STVF capability of simulating } \\
\text { SPDM for simple contact tasks }\end{array}$ & 5 \\
\hline ORU & ORU test & $\begin{array}{l}\text { Demonstrate STVF capability of } \\
\text { simulating SPDM for general contact tasks }\end{array}$ & 2 \\
\hline $\mathrm{OE}$ & Operator evaluation & $\begin{array}{l}\text { Get the operators' feeling about the facility } \\
\text { by Cooper-Harper rating (not used for } \\
\text { judging the facility's validity) }\end{array}$ & 2 \\
\hline FT & Flight tests & $\begin{array}{l}\text { Validate STVF capability of simulating } \\
\text { SPDM for real ORU tasks }\end{array}$ & $\mathrm{N} / \mathrm{A}$ \\
\hline \multicolumn{3}{|c|}{ Total no. of test runs } & 22 \\
\hline
\end{tabular}

-Arm pitch plane change feature

-Singularity management feature

The validity of the STVF in one control mode does not necessarily guarantee that in another mode. It would be ideal if we can exercise as many modes and features as possible in the proposed validation test runs. The primary choice of the control modes for the limited test runs will be the MAM mode with or without FMA feature selected, because this is the basic control mode and feature for ORU contact tasks. The POHS is also an important feature for the alignment before contact takes place and hence it will also be investigated in the validation.

\subsubsection{Motion Speed and Trajectory}

For free-motion tests, it is recommended to use the maximum or the minimum tip speed. The maximum speed is commanded in order to have maximum observability of the dynamics and the minimum speed is for checking the sensitivity and resolution of the STVF. Since the workspace of the STVF robot is limited to a box-like 3D volume whose minimum side is only $0.6 \mathrm{~m}$ (in the horizontal plane) and maximum side is $1.32 \mathrm{~m}$ (in the vertical direction), it has to be ensured that the test motion trajectory is entirely within this volume. For a given workspace, higher speed will mean shorter operation duration. On the other hand, the total operation time should be long enough to allow for the reach of steady state and for the observation of low frequency behavior of the sys- tem dynamics. For the configuration of the SPDM operating from the tip of the Canadarm2, the natural frequency is only about $0.4 \mathrm{~Hz}$.

In the free space test, the SPDM brakes may be applied suddenly in order to maximally excite dynamic modes and show the system's stopping performance. Such a test is challenging for the STVF robot because the hydraulic robot does not have joint brakes and it has to use its control systems to perform the "braking." The ground robot must demonstrate its capability of emulating the SPDM dynamics in response to the application of the brakes.

For constrained-motion tests, commanded speeds will depend on specific constraint cases. Operational speed should be made lower when the constraint becomes stiffer. In general, the tip speed should be limited to the vernier level during a contact operation ( $\leqslant 10 \mathrm{~mm} / \mathrm{s}$ for SPDM).

\section{TEST CASES}

Based upon the foregoing discussion of approaches and considerations, a set of validation test categories has been defined, as summarized in Table I. Each test category consists of a number of test runs (cases) particularly designed for checking a special level of validity of the facility. These test cases in each of the test categories reflect different test conditions within the scope of that category. Each test run is identified using an ID name representing its test category and a 


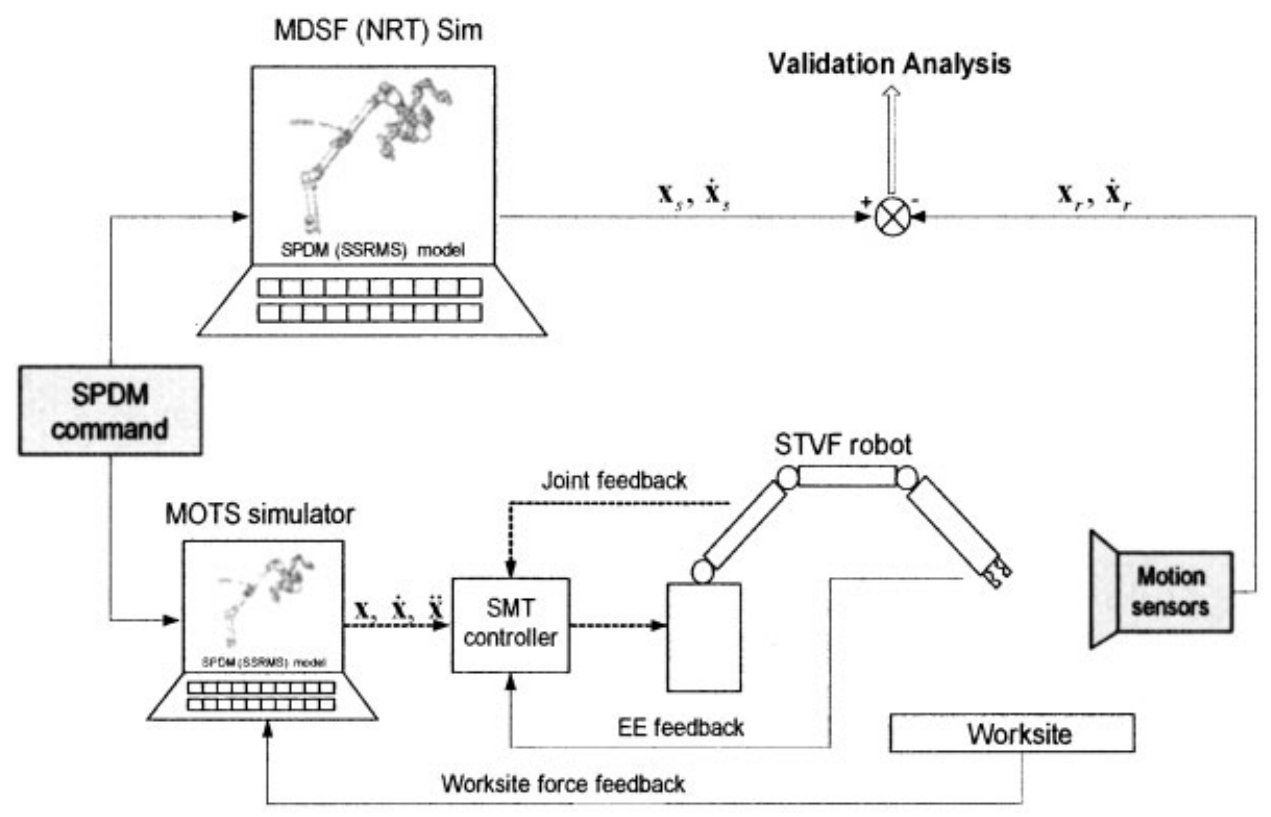

Figure 5. Concept diagram of the free-space (FS) test.

number representing its run number. For example, AF-3 represents the third test run of the applied-force test category.

The planned test categories are conceptually illustrated by the diagrams in Figures 5-10.

In each diagram the top path represents the pure software simulation performed by the MDSF and the bottom path is the software-hardware combined simulation done by the STVF. Their output results are compared against the validation criteria defined in Section 5. The MDSF simulation, used as reference for comparison, does not need to be run in real-time.

It has been a widely held view that the subjective OE test would not add much value to the otherwise

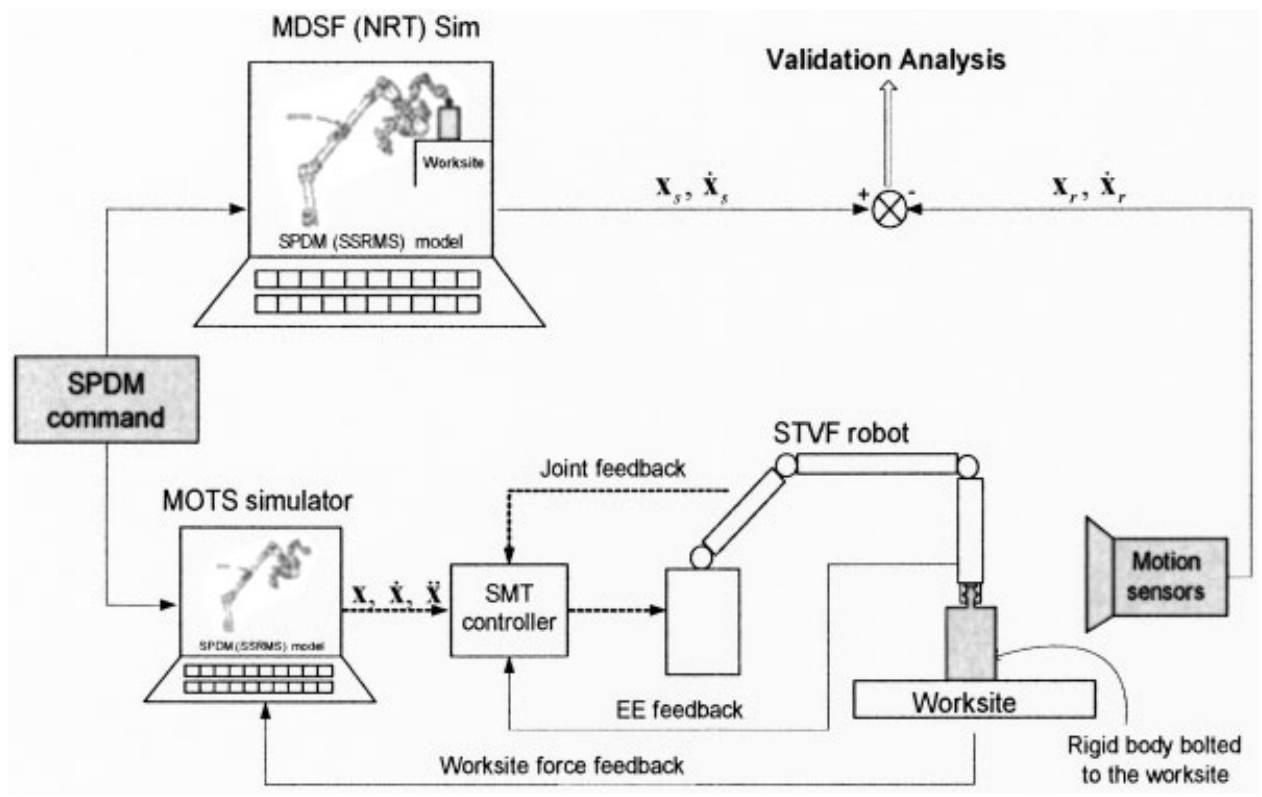

Figure 6. Concept diagram of the rigidly constrained (RC) test. 


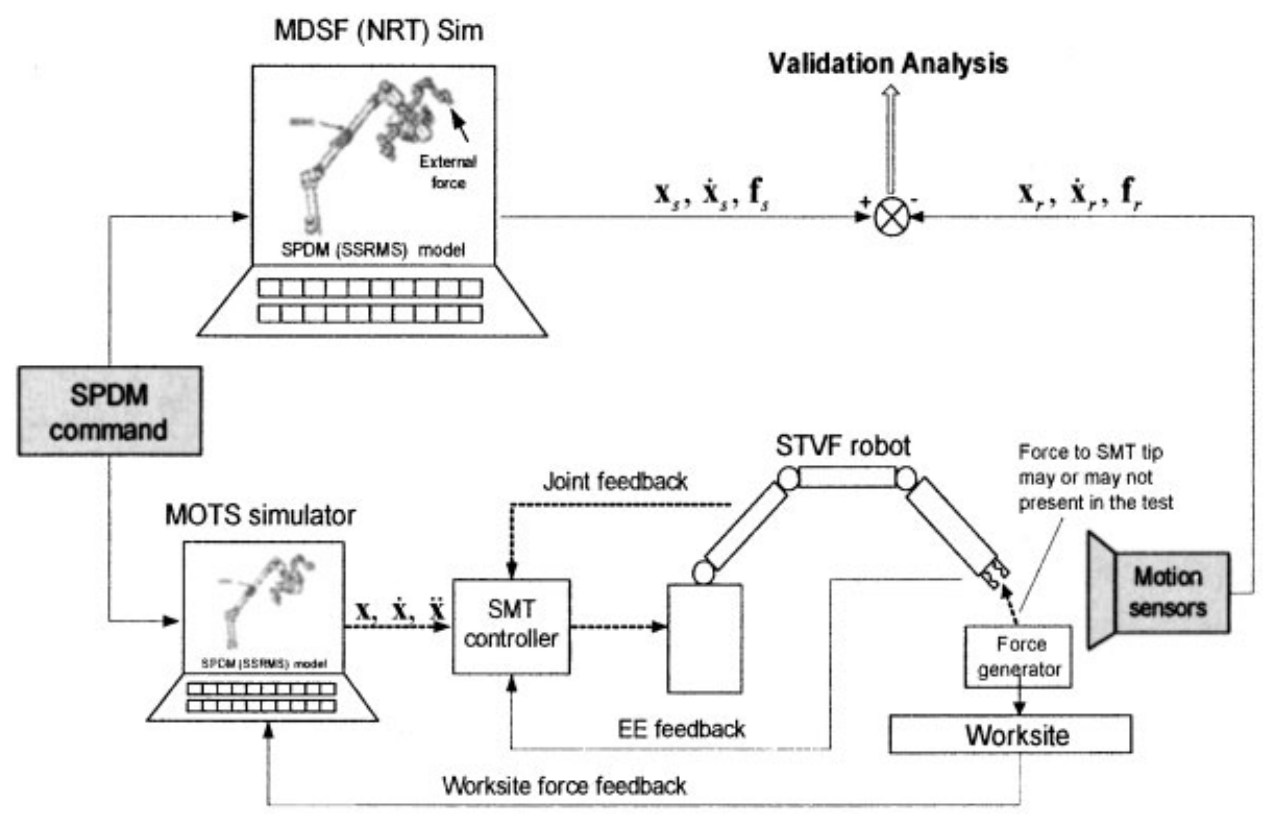

Figure 7. Concept diagram of the applied-force (AF) test.

rigorous engineering judgment required for the STVF validation and, therefore, this test category is not planned for the judgment of the validity of the facility. Instead, it is used to get some feeling about the operation of the facility from experienced operators such as crew members or operation engineers.
The complexity of the test categories varies from the simplest free-space test (Figure 5) to the most complicated full ORU test (Figure 10). It is very important to understand that this specially designed from-simple-to-complex test strategy is necessary for understanding and final judgment of the complex

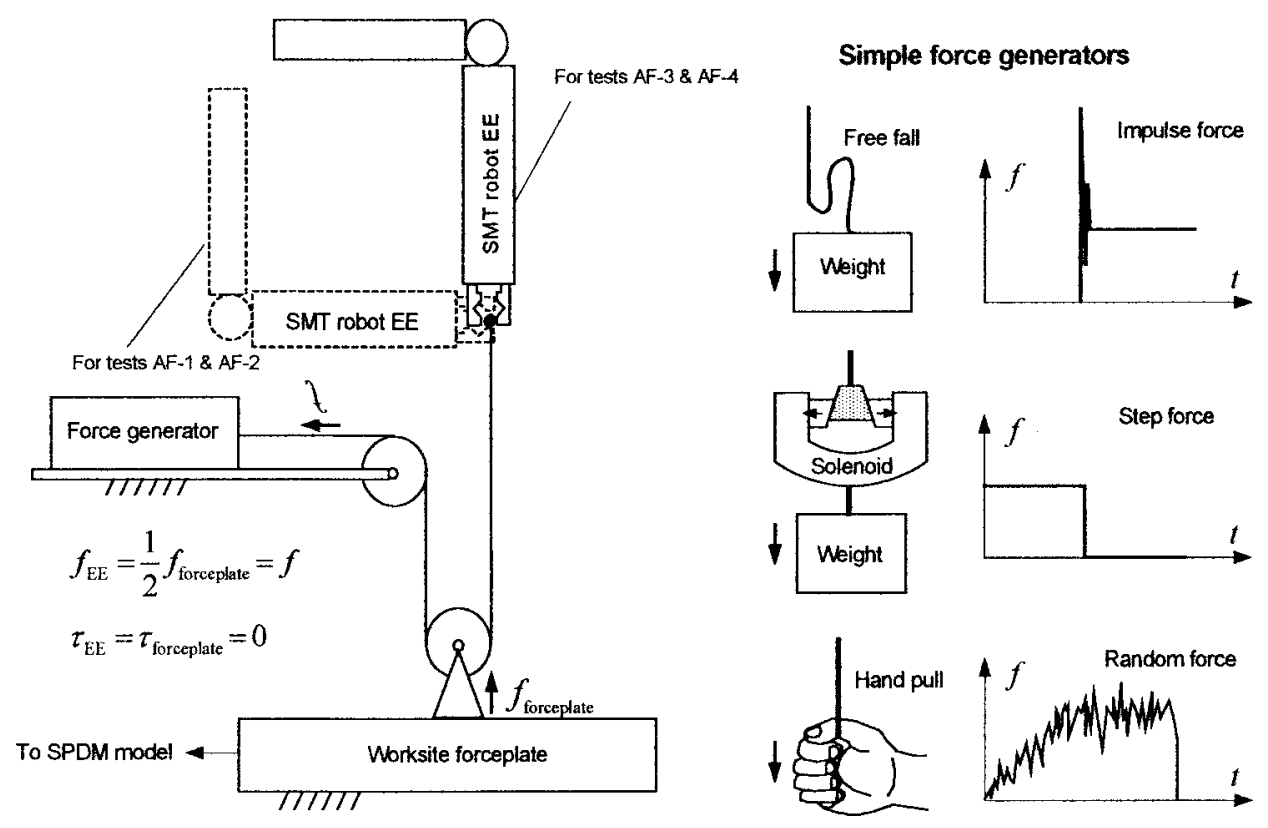

Figure 8. Examples of applied-force generator for AF tests. 


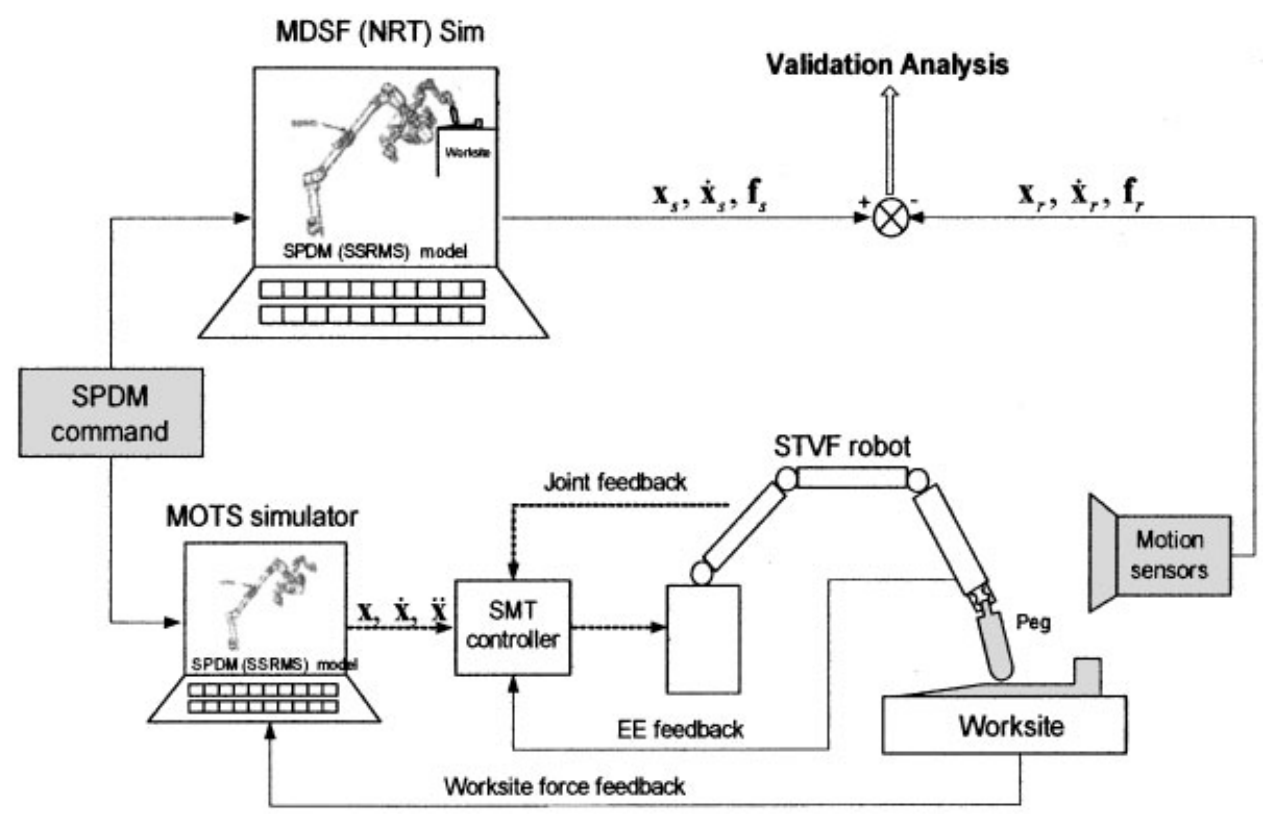

Figure 9. Concept diagram of simple-contact (SCD) test.

STVF dynamics system. Because of the lack of validated ORU contact-dynamics model parameters, we cannot immediately jump to the ORU test without going through simpler and much more understandable test cases first. These intermediate test categories include the rigidly constrained test, the applied-force test, and the simple contact test. Another originally recommeded test category which uses a spring constraint between the robot tip and the worksite is deleted for saving the validation cost.

From the past validation experiences, we believe that a total of 22 formal test runs would be adequate.

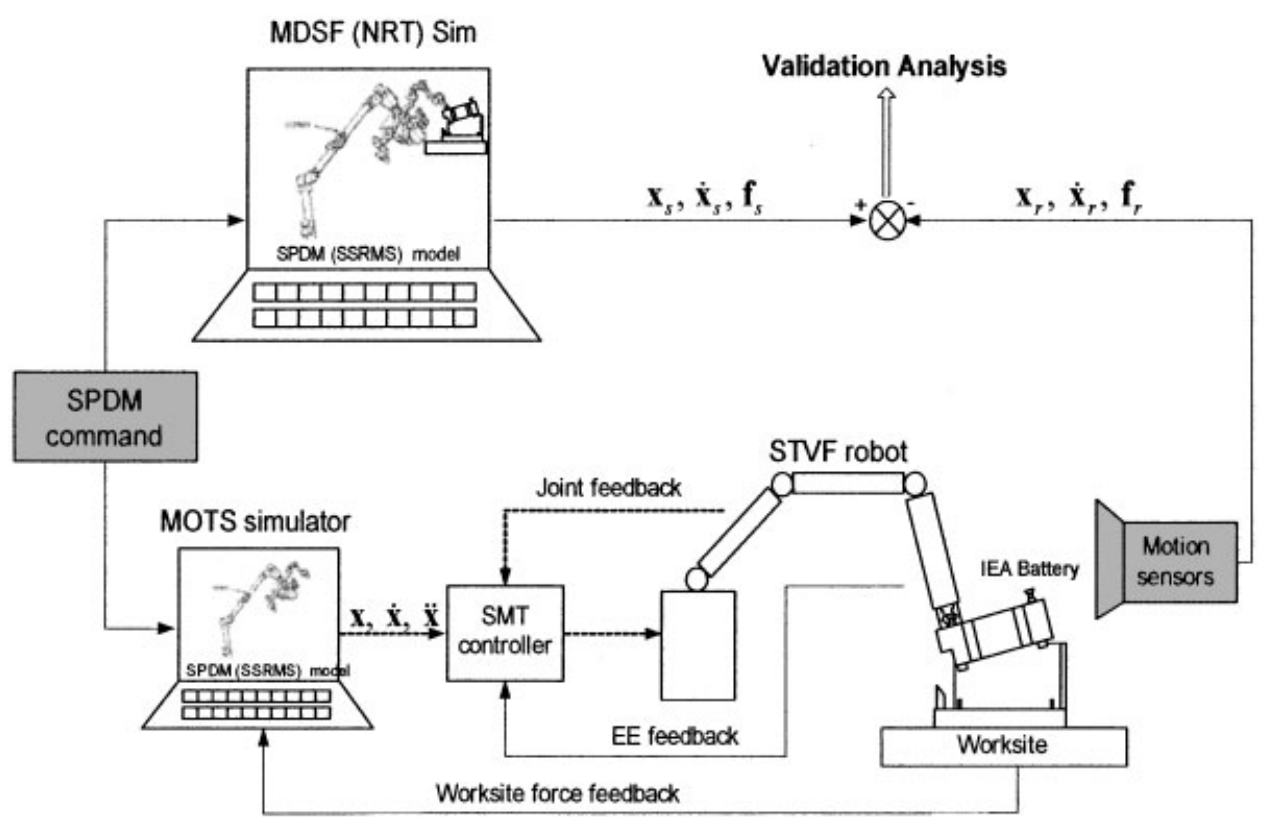

Figure 10. Representative ORU test. 
Among the total runs, seven are free-space runs, four are free-space but applying tip force runs, nine are constrained or contact runs, and the final two are operator-in-the-loop test runs. In our opinion, the 14 runs in the RC, AF, SCD, and ORU test categories are most important. Each of the test categories has been defined in the validation plan. All the test cases are detailed in the validation plan. Because of the space limitations, we cannot describe them in detail here.

\section{PASS/FAIL CRITERIA}

In the validation process, the maximum allowed tolerances for the errors between the target simulation or test output and the reference simulation or test output will have to be established. These error tolerances are usually referred to as validation criteria. Validation criteria have to be carefully developed and agreed upon by the technical community including the SPDM developers and users. This section describes the validation criteria and how they are applied to the validation process.

\subsection{Comparison Methods}

There are two kinds of basic comparison strategies in the validation process. One is performance-based and the other is task-based. The performance-based comparison checks the detailed dynamic performance along the time history of the simulated operations. Typically, it compares the transient peaks, steadystate values, frequencies, and phase differences of the simulated dynamic responses against the corresponding quantities of a reference simulation or physical test. The task-based comparison checks whether the simulated task is accomplished as expected without looking into the detailed time histories of the corresponding dynamic performance. It compares only the major operational status such as success (e.g., an ORU is inserted) or fail (e.g., jammed or missed), final misalignments, total time of operation, maximum load, etc. Obviously, the performance-based strategy is more precise but it requires much more effort of engineering analysis, especially when one needs to distinguish errors from dynamics model and those from numerical process and/or measurement systems. The task-based strategy, on the other hand, is relatively easier to apply because it avoids looking into detailed dynamic responses. As a result, it is more suitable for gross validation. The task-based comparison is, in fact, more suitable for validating contact dynamics (CD) simulations with complex contact interfaces, because in such cases detailed dynamic responses are extremely difficult to predict, understand, and analyze.

\subsection{Validation Criteria}

Corresponding to the two comparison methods described in Section 5.1, two different levels of validation criteria are proposed, namely,

1. Task-based validation criteria and

2. Performance-based validation criteria.

The task-based criteria are designed for taskbased comparison method. The performance-based criteria, on the other hand, are designed for performance-based comparison method. The main motivation for defining the two levels of criteria is to maximize the validation tests or runs with limited budget/time. As we know, for contact operations, the analysis and interpretation of simulation results will be more difficult and time consuming. On the other hand, contact dynamics responses vary significantly from one case to another. A small number of runs will not be sufficient to cover necessary aspects but a large number of tests may not be realistic for cost and time limitations.

The foregoing fact motivated us to develop the two-step validation procedure as described in Figure 11. At first step, a large number of runs were screened by the task-based criteria. At the second step, only a selected number of the runs, which have passed the first step, will be screened by the performance-based criteria. In other words, all the validation runs will have to pass the task-based criteria and only a small part of all the validation runs are required to pass the performance based criteria. Of course, the failed runs in both steps will have to be investigated and retested.

As a matter of fact, the above-mentioned twostep process has been practiced in our past validation works at MDR for Canadarm and Canadarm2. It is also a very common practice for hardware testing. However, this is the first time it is formally defined and documented in a validation process.

\subsubsection{Task-Based Validation Criteria}

The task-based validation criteria represent a high level of engineering judgment for contact tests. There are no existing references available for this type of criteria although this kind of high level checking has been practiced in the past. Based on the past 


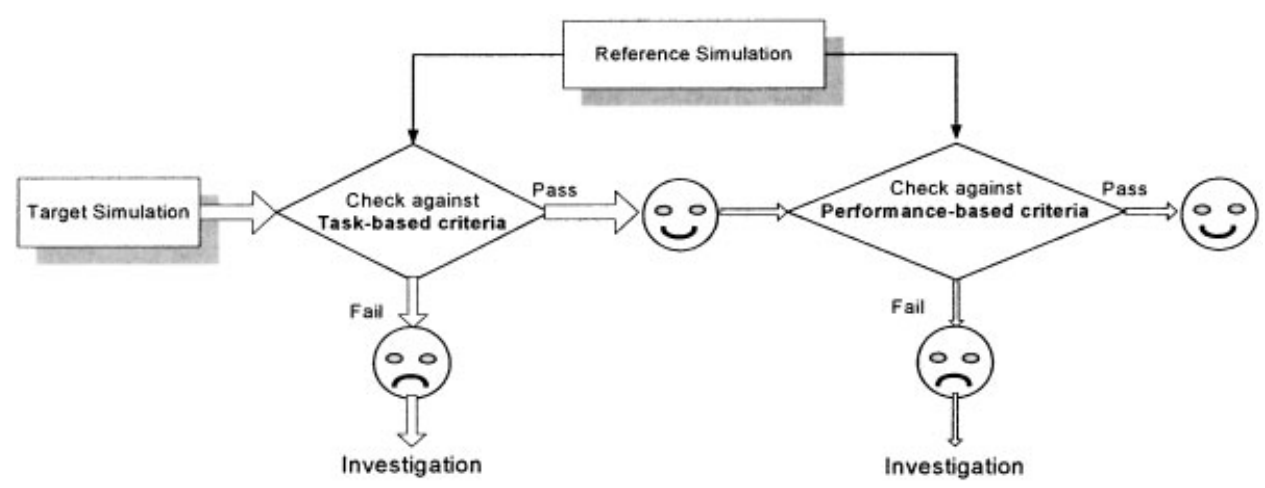

Figure 11. Two levels of criteria in the validation process.

experiences of $C D$ validation and the specific nature of ORU contact tasks, we define a set of the taskbased criteria for contact tasks, as given in Table II. It should be pointed out that the task-based validation criteria are not suitable for validation of noncontact tasks because they have many fewer uncertainties than their contact counterparts. For the noncontact test cases, the performance-based criteria defined in Section 5.2.2 should be used.

Because SPDM is flexible and it moves very slow (normally $5 \mathrm{~mm} / \mathrm{s}$ or less) during contact operations, any bounces resulting from impact will not be significant. This fact has been shown in our simulation tests. Therefore, the criterion regarding bouncing is not important.

Please note that the criteria regarding the final misalignments depend on the contact geometry interface and, thus, their values vary from one ORU to another. However, it is not difficult to compute them if one knows the geometry data of the contact interface of the ORU of interest. In fact, during a test, one may not have to really measure and check the final mis- alignments. Because the criteria were designed just to guarantee the ORU within the envelope of the bolt drive, the above computed criteria must be satisfied if the ORU can be bolted down to its final place using a normal end-effector driving torque.

The purpose of defining comparison criterion regarding time comes from such a fact that we observed situations in our past hardware testing where an ORU task was completed but it took a substantially longer time (i.e., twice or many times longer) than it should. The long operation time was caused by some kind of temporary jamming or slow creeping in the course of the ORU insertion or extraction. Obviously, if such a case happens, we would not consider the task successful although the ORU has eventually been placed into its target position. The only criterion being capable of catching this kind of situation would be the time criterion. The reason for setting the time criterion to $30 \%$ is because we believe that if an ORU task takes $30 \%$ more or less time to complete, an average operator would unlikely notice the time

Table II. Task-based validation criteria.

\begin{tabular}{ll}
\hline \hline Quantity & \multicolumn{1}{c}{ Criteria (error tolerances) } \\
\hline Overall & $\begin{array}{l}\text { The main trends of dynamic responses look similar } \\
\text { without significant and unexplainable abnormalities from } \\
\text { operator's point of view. } \\
\text { If the task requires follow-on bolt driving, the final } \\
\text { misalignments should be within the envelope of the bolt } \\
\text { head. }\end{array}$ \\
$\begin{array}{l}\text { Final } \\
\text { misalignments }\end{array}$ & $\begin{array}{l}\text { Following the reference (whether jamming or not) within } \\
\text { Jamming }\end{array}$ \\
$\begin{array}{l}\text { Following the reference within } 30 \% \text { differences in time. } \\
\text { Bouncing }\end{array}$ & $\begin{array}{l}\text { Force: } 40 \% \text { or } 20 \text { N, whichever is larger } \\
\text { Moment: } 40 \% \text { or } 10 \text { Nm, whichever is larger }\end{array}$ \\
Maximum POR & $\begin{array}{l}\text { Force: } 10 \% \text { or } 10 \mathrm{~N}, \text { whichever is larger } \\
\text { Moment: } 10 \% \text { or } 5 \text { Nm, whichever is larger }\end{array}$ \\
Final POR load & The total time used to complete the task must be within \\
Completion time & $30 \%$ difference.
\end{tabular}


Table III. Performance-based validation criteria. ${ }^{\mathrm{a}}$

\begin{tabular}{|c|c|c|c|c|c|c|}
\hline \multirow[b]{2}{*}{ Measured quantity } & \multirow[b]{2}{*}{ Tip constraint } & \multirow[b]{2}{*}{ State } & \multicolumn{2}{|c|}{ Criteria (sim-to-test) } & \multicolumn{2}{|c|}{ References (sim-to-sim) } \\
\hline & & & Relative & Absolute & canadarm2 & canadarm \\
\hline POR position & $\begin{array}{c}\text { Unconstrained } \\
\text { Constrained }\end{array}$ & $\begin{array}{c}\text { Peak } \\
\text { Steady-state } \\
\text { Peak } \\
\text { Steady-state }\end{array}$ & $\begin{array}{r}15 \% \\
5 \%\end{array}$ & $\begin{array}{l}0.013 \mathrm{~m} \\
0.006 \mathrm{~m} \\
0.026 \mathrm{~m} \\
0.004 \mathrm{~m}\end{array}$ & $\begin{array}{c}0.06 \mathrm{~m} \\
0.03 \mathrm{~m} \\
\text { unavailable } \\
\text { unavailable }\end{array}$ & $\begin{array}{c}0.061 \mathrm{~m} \\
0.031 \mathrm{~m} \\
\text { unavailable } \\
\text { unavailable }\end{array}$ \\
\hline POR orientation & $\begin{array}{c}\text { Unconstrained } \\
\text { Constrained }\end{array}$ & $\begin{array}{c}\text { Peak } \\
\text { Steady-state } \\
\text { Peak } \\
\text { Steady-state }\end{array}$ & $\begin{array}{r}15 \% \\
5 \%\end{array}$ & $\begin{array}{l}0.53 \text { deg } \\
0.20 \text { deg } \\
1.00 \text { deg } \\
0.20 \text { deg }\end{array}$ & $\begin{array}{c}1.0 \text { deg } \\
0.2 \text { deg } \\
\text { unavailable } \\
\text { unavailable }\end{array}$ & $\begin{array}{c}1.0 \text { deg } \\
0.2 \text { deg } \\
\text { unavailable } \\
\text { unavailable }\end{array}$ \\
\hline POR linear velocity & $\begin{array}{l}\text { Unconstrained } \\
\text { Constrained }\end{array}$ & $\begin{array}{c}\text { Peak } \\
\text { Steady-state } \\
\text { Peak } \\
\text { Steady-state }\end{array}$ & $\begin{array}{l}30 \% \\
10 \%\end{array}$ & $\begin{array}{l}0.005 \mathrm{~m} / \mathrm{s} \\
0.001 \mathrm{~m} / \mathrm{s} \\
0.010 \mathrm{~m} / \mathrm{s} \\
0.001 \mathrm{~m} / \mathrm{s}\end{array}$ & $\begin{array}{c}0.015 \mathrm{~m} / \mathrm{s} \\
\text { unavailable } \\
\text { unavailable } \\
\text { unavailable }\end{array}$ & $\begin{array}{c}0.015 \mathrm{~m} / \mathrm{s} \\
0.003 \mathrm{~m} / \mathrm{s} \\
\text { unavailable } \\
\text { unavailable }\end{array}$ \\
\hline POR Ang. velocity & $\begin{array}{l}\text { Unconstrained } \\
\text { Constrained }\end{array}$ & $\begin{array}{c}\text { Peak } \\
\text { Steady-state } \\
\text { Peak } \\
\text { Steady-state }\end{array}$ & $\begin{array}{l}30 \% \\
10 \%\end{array}$ & $\begin{array}{l}0.05 \mathrm{deg} / \mathrm{s} \\
0.02 \mathrm{deg} / \mathrm{s} \\
0.08 \mathrm{deg} / \mathrm{s} \\
0.02 \mathrm{deg} / \mathrm{s}\end{array}$ & $\begin{array}{c}0.05 \mathrm{deg} / \mathrm{s} \\
\text { unavailable } \\
\text { unavailable } \\
\text { unavailable }\end{array}$ & $\begin{array}{l}0.05 \mathrm{deg} / \mathrm{s} \\
0.025 \mathrm{deg} / \mathrm{s} \\
\text { unavailable } \\
\text { unavailable }\end{array}$ \\
\hline POR force & $\begin{array}{l}\text { Unconstrained } \\
\text { Constrained }\end{array}$ & $\begin{array}{c}\text { Peak } \\
\text { Steady-state } \\
\text { Peak } \\
\text { Steady-state }\end{array}$ & $\begin{array}{l}30 \% \\
10 \%\end{array}$ & $\begin{array}{c}15 \mathrm{~N} \\
5 \mathrm{~N}\end{array}$ & $\begin{array}{l}\text { unavailable } \\
\text { unavailable } \\
\text { unavailable } \\
\text { unavailable }\end{array}$ & $\begin{array}{l}\text { unavailable } \\
\text { unavailable } \\
\text { unavailable } \\
\text { unavailable }\end{array}$ \\
\hline POR moment & $\begin{array}{c}\text { Unconstrained } \\
\text { Constrained }\end{array}$ & $\begin{array}{c}\text { Peak } \\
\text { Steady-state } \\
\text { Peak } \\
\text { Steady-state }\end{array}$ & $\begin{array}{l}30 \% \\
10 \%\end{array}$ & $\begin{array}{l}8 \mathrm{Nm} \\
3 \mathrm{Nm}\end{array}$ & $\begin{array}{l}\text { unavailable } \\
\text { unavailable } \\
\text { unavailable } \\
\text { unavailable }\end{array}$ & $\begin{array}{l}\text { unavailable } \\
\text { unavailable } \\
\text { unavailable } \\
\text { unavailable }\end{array}$ \\
\hline Dominant frequency & $\begin{array}{l}\text { Unconstrained } \\
\text { Constrained }\end{array}$ & $\begin{array}{l}\text { Frequency } \\
\text { Phase shift } \\
\text { Frequency } \\
\text { Phase shift }\end{array}$ & $30 \%$ & & $\begin{array}{c}15 \% \\
\text { unavailable } \\
\text { unavailable } \\
\text { unavailable }\end{array}$ & $\begin{array}{c}25 \% \\
\text { unavailable } \\
\text { unavailable } \\
\text { unavailable }\end{array}$ \\
\hline
\end{tabular}

aThe criteria for unconstrained motion were derived with slight adjustment. The criteria for constrained motion were proposed based on R\&D CD validation and SPDM test experiences. Legend: Unconstrained-motion direction along which no physical constraints exist, i.e., noncontact motion, Constrained-motion direction along which a physical constraint exists, i.e., contact motion, Peak-The transient peak of the highest motion wave; peak value should be averaged from several data points, Steady-state-the steady-state in the final motion period.

difference. Longer time difference would normally be noticeable by the human operator.

\subsubsection{Performance-Based Validation Criteria}

Some performance-based validation criteria have been developed in MD Robotics Ltd. (formerly Spar Aerospace Ltd.) for Canadarm and Canadarm2. However, these criteria are of very limited use in the scope of this validation plan because, comparing the SPDM to Canadarm2 or Canadarm, there are significant differences in size and the nature of their tasks plus both Canadarm2 and Canadarm criteria are for free-space (noncontact) motions only. Therefore, validation criteria for closed kinematics chains and for the intermittent contact regime encountered during ORU replacement tasks have to be defined from scratch.

Based on the above-mentioned validation experience for Canadarm ${ }^{11}$ and the specifications of the $\mathrm{SPDM}^{10}$ and Canadarm $2{ }^{12}$ we derived a set of STVF performance-based validation criteria for unconstrained motion, as shown in Table III. The derived criteria numbers have been rounded to the nearest $0.001 \mathrm{~m}$ (i.e., $\mathrm{mm}$ ) for linear quantities and $0.01^{\circ}$ for angular quantities, which is a similar fashion having been used in the development of the Canadarm 2 simto-sim validation criteria.

For contact operations or constrained motions, there are no documented criteria available from past practice for references. Generally speaking, the 

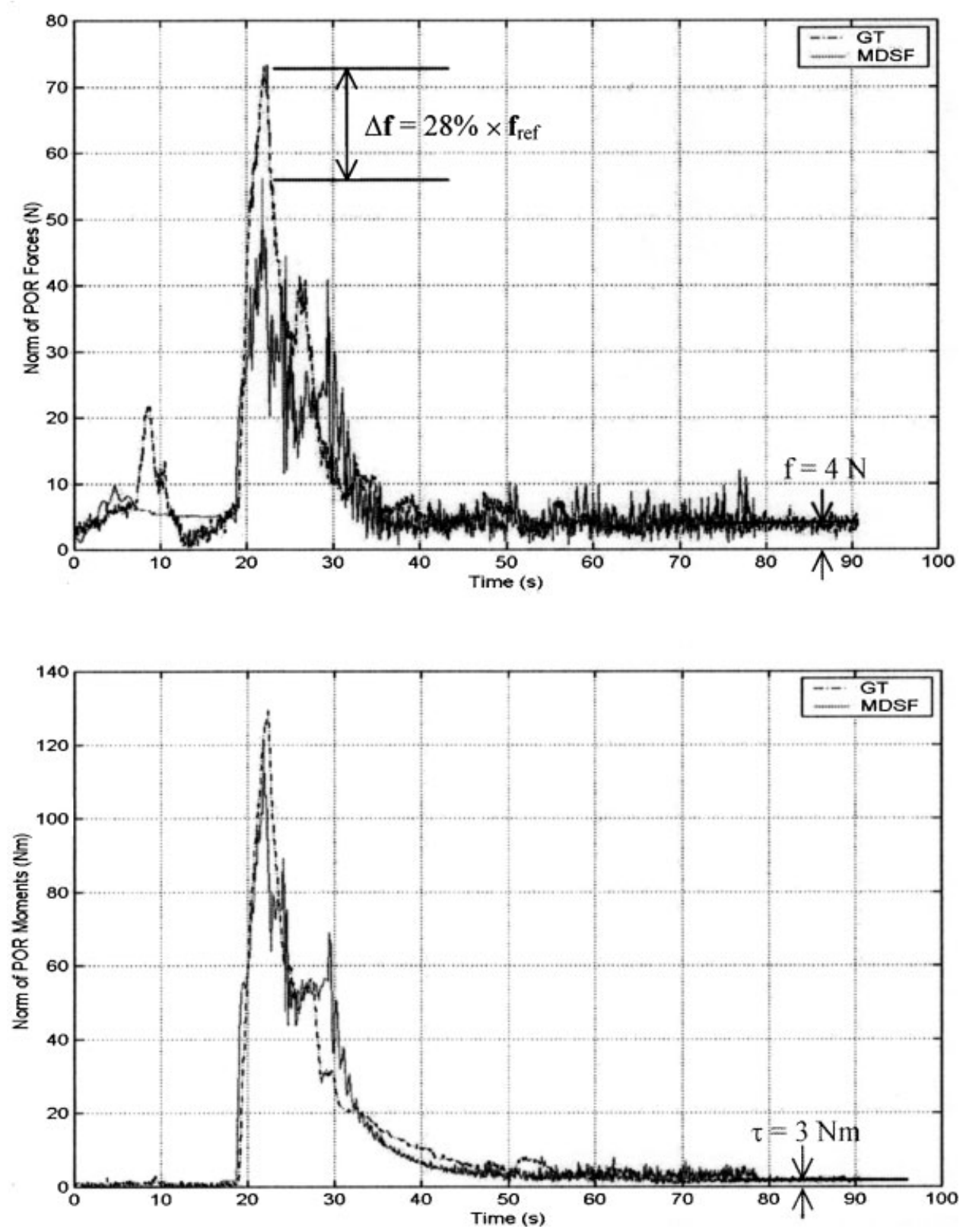

Figure 12. Simulation versus hardware comparison of SPDM grasping a payload test.

tolerance on a transient peak for a contact motion should be higher than that of a noncontact motion because the transient motion caused by contact/impact is more unpredictable than the free-space motion. On the other hand, the tolerance on a steady state for a constrained contact motion should be lower than its noncontact counterpart because the physical constraint in the contact interface helps to reduce the deviation in dynamic motion.

In addition, for a constrained motion, if a geom- etry constraint in the contact interface is tighter than the position or orientation criteria given in Table III, then the former should be used to replace the corresponding criteria from the table. This is because the physical constraints in geometry cannot be violated. For example, if the clearance between a matching peg and hole hardware is only $1 \mathrm{~mm}$, then the tip position criterion for the test should be just $1 \mathrm{~mm}$ instead of the $4 \mathrm{~mm}$ steady-state position criterion given in Table III. 


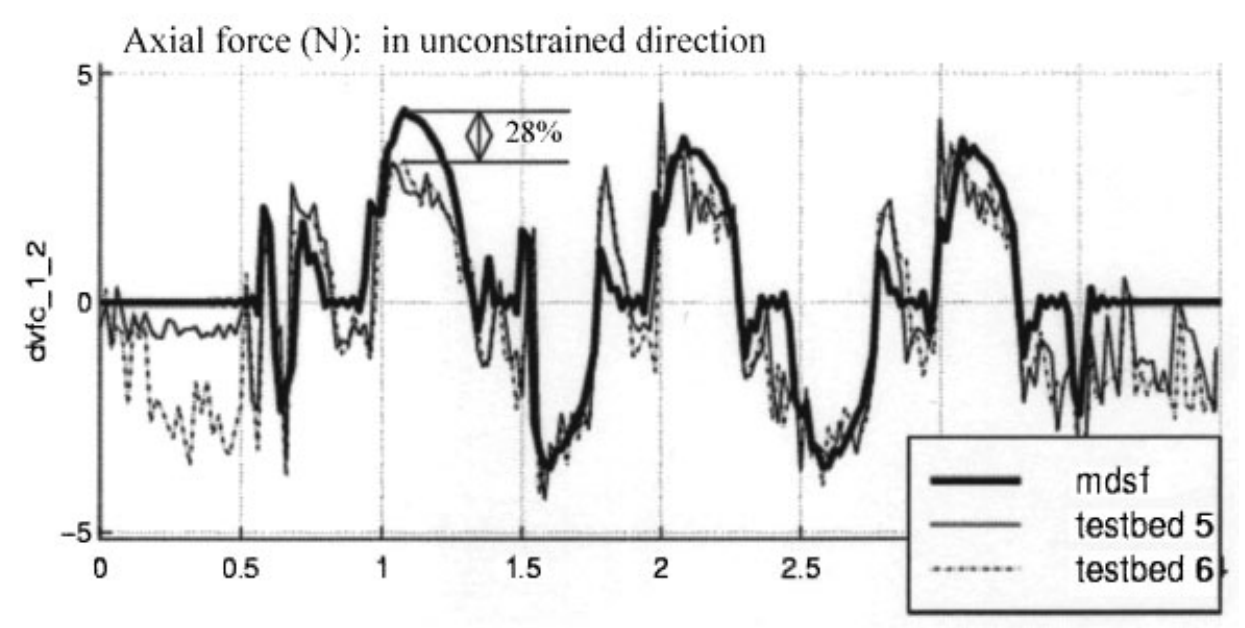

Lateral force $(\mathrm{N})$ : in constrained direction
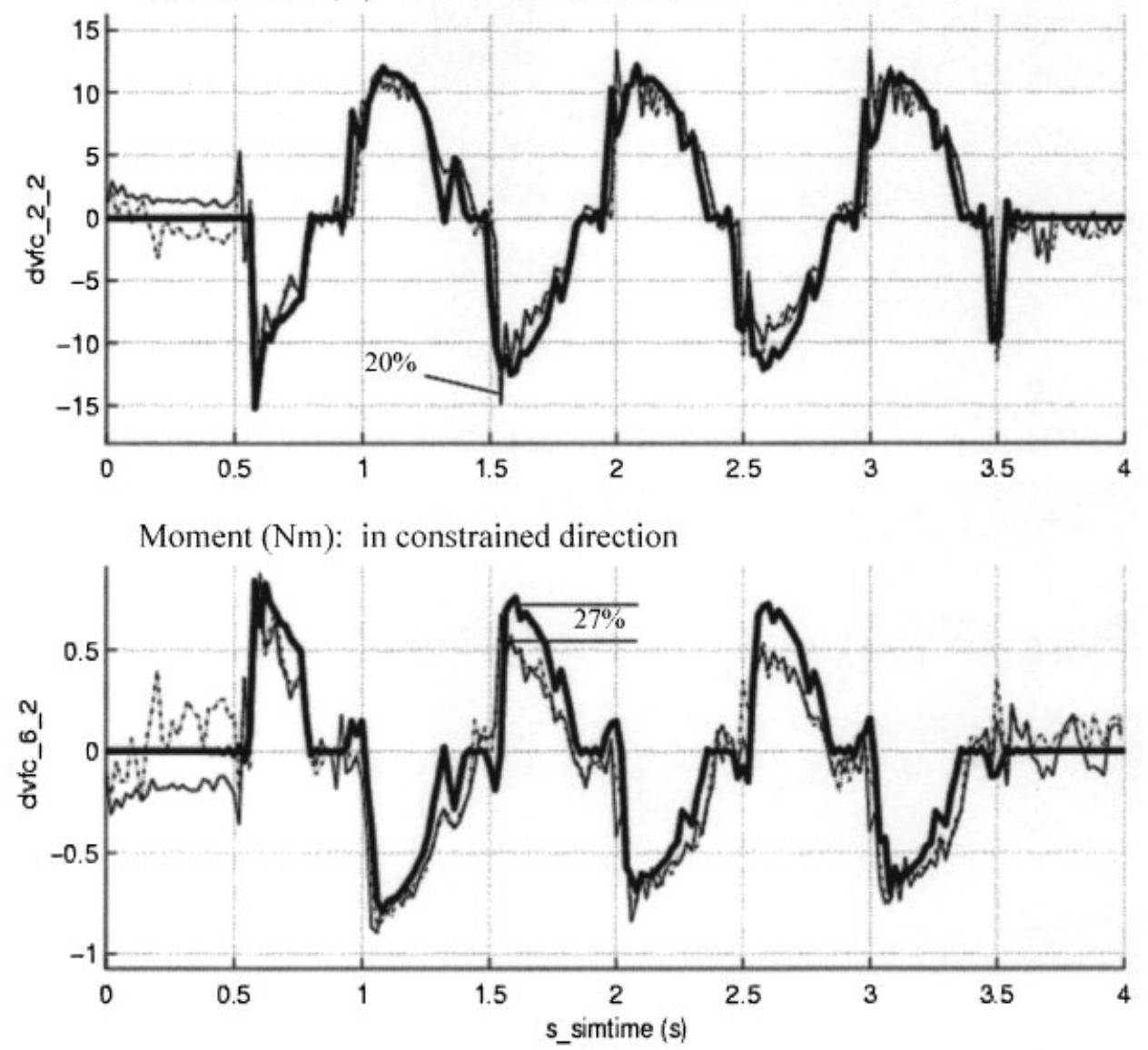

Figure 13. Example plots from the validation of MDR's CD simulation of the U. Vic robot performing a peg-in-hole operation against the hardware test of the robot.

Regarding the force criteria, other than coming up with some numbers ad hoc, we visited the records of the contact dynamics validation works accomplished in the past, such as
- MDSF simulation versus Whitney's published analytical and experimental results for peg-in-hole contact task, which is documented in ref. 9;

- MDSF simulation versus a ground testbed test 
of SPDM gasping a fixed micro fixture, for example, shown in Figure 12; and

- MDSF simulation versus University of Victoria robotics lab test for peg-in-hole contact task, which is documented in ref. 13 and, for example, shown in Figure 13.

All of the above validation results have been made known to the technical community not only in MDR but also in major space agencies such as CSA, NASA, ESA, and NASDA through presentations, published papers, and other forms of technical communications. Some of the results have been even published in high-quality peer-reviewed scientific journals. As a result, we can confidently claim that these validation results have been, in fact, accepted by the technical community at large. Based upon this fact and the above-listed contact dynamics validation results, we proposed a set of validation criteria for constrained motion, as shown in Table III. Some of the less important criteria are still undecided and hence, their values are left blank in the table.

In fact, the Canadarm's validation criteria had not been finalized until years after the launch of the arm. ${ }^{11}$ The Canadarm2 validation criteria had also been developed over a course of several years. ${ }^{14}$ Similarly, the unprecedented validation criteria for contact motion being proposed in this section are still not final at this moment. Further improvements to the criteria based on additional rationale and more supporting evidences are expected. They will be finalized when the flight data of the SPDM become available after its launch in 2006.

\section{CONCLUSIONS}

A methodology for validating the ground-based, hardware-in-the-loop space-robot simulator SPDM Task Verification Facility has been developed. Because of the complex nature of the facility, a two-step approach was proposed; one is at a gross, higher level and the other at a more detailed engineering level. The strategy of developing the validation tests is to start from simple and well-understood cases, gradually extend the complexity of the tests, and finally to the most representative ORU contact cases. The validation test cases were particularly designed to address the main concerns and issues regarding the design and operation of the simulation facility. Finally, a set of validation criteria (error tolerances) has been developed based on the objectives of the validation and the experiences of past simulation validations, as well as the specifics of the STVF and the SPDM systems.

\section{ACKNOWLEDGMENTS}

This work would have been impossible without the technical support from the STVF development team led by Dr. Jean-Claude Piedboeuf and Dr. Eric Martin of the CSA, the STVF sponsor and operations team led by Dr. Alan Robinson, Dr. Banu Kalaycioglu, and K. Pudwalski of CSA, the SPDM systems experts R. Mukherji, R. Carr, Dr. K. Buhariwala, Dr. R. Ravindran, and Dr. P. Nguyen of MD Robotics.

\section{REFERENCES}

1. D.A. Bassett and A. Abramovici, Special purpose dexterous manipulator (SPDM) requirements verification, European Space Agency, Special Publication, ESA SP, 1999, pp. 43-48.

2. P. Feighan, A. Dagnino, K. Chrystall, and P. Wojcik, Mobile servicing center (space station remote manipulator system and mobile remote servicer base system) overview, Prog Astronaut Aeronaut 161 (1994), 421.

3. J.-C. Piedboeuf, J. De Carufel, F. Aghili, and E. Dupuis, Task verification facility for the Canadian special purpose dextrous manipulator, Proc IEEE Int Conf on Robotics and Automation Detroit, 1999, Vol. 3, pp. 10771083.

4. W.H. Zhu, J.-C. Piedboeuf, and Y. Gonthier, Emulation of a space robot using a hydraulic manipulator on ground, Proc IEEE Int Conf on Robotics and Automation, Washington, DC, 2002, Vol. 3, pp. 2315-2320.

5. S. Veerasarmy and J. Hubbard, Real-time berthing for space station and space shuttle, Simulation 57:(1) (1991), 31-38.

6. S. Ananthakrishnan, R. Teders, and K. Alder, Role of estimation in real-time contact dynamics enhancement of space station engineering facility, IEEE Robot Autom Mag (1996), 20-28.

7. R. Krenn and B. Schaefer, Limitations of hardware-inthe-loop simulations of space robotics dynamics using industrial robots, European Space Agency, Special Publication, ESA SP, 1999, pp. 681-686.

8. J. De Carufel, E. Martin, and J.-C. Piedboeuf, Control strategies for hardware-in-the-loop simulation of flexible space robots, IEE Proc Control Theory Appl 147:(6) (2000), 569-579.

9. O. Ma, K. Buhariwala, N. Roger, J. Maclean, and R. Carr, MDSF-a generic development and simulation facility for flexible, complex robotic systems, Robotica 15:(1) (1997), 49-62.

10. P. Fullford, Special purpose dexterous manipulator (SPDM) specification, MD Robotics Technical Document: SPAR-SS-SG-2899, Revision C, 1999.

11. B.C. Palmer, Shuttle remote manipulator system 
simulation validation plan, NASA Document: JSC37938, 1998.

12. M. Brouillette, Space station remote manipulator system (SSRMS) specification, MD Robotics Technical Document: SPAR-SS-SG-0379, Revision G, 1995.

13. J. Van Vliet, I. Sharf, and O. Ma, Experimental valida- tion of contact dynamics simulation of constrained robotic tasks, Int J Robot Res 19:(12) (2000), 1203-1217.

14. C. Trudel, Mobile servicing system simulation validation plan, Volume 1: space station remote manipulator system (SSRMS) simulation validation, Canadian Space Agency CAS-SS-PL-0007, Revision 3, 1997. 